Progress in Ceramic Science

Vol. 3. Edited by Dr. J. E. Burke. Pp. vii + 262. (London and Now York: Pergamon Press, 1963.) 80s. net.

$\mathrm{T}$ $\mathrm{HE}$ second volume in this series was reviewed on p. 932 of the March 9, 1963, issue of Nature. The present volume contains four essays, the first by Prof. G. W. Brindley (Pennsylvania State University), "Crystallographic Aspects of Some Decomposition and Recrystallization Reactions", in which orientation relationships betweon parent and product phases are discussed and illustrated, including the aluminium hydrous silicatesa field which Prof. Brindley has made especially his own. The second essay, by F. M. Ernsberger (Pittsburgh Plate Glass Co.), deals with the current status of the Griffith crack theory of glass strength. He surveys techniques (ion-exchange, pulsed-stress, bifluoride etch and sodium-vapour treatment) for the direct detection of Griffith cracks. It is suggested that mechanicaldamage cracks form a distinct class of strength-impairing structures, and that the description 'Griffith crack' should be reserved for such defects, distinguishing them from hypothetical intrinsic flaws which are presumably responsible for the failure of glass with damage-free surfaces. There appears to be a good deal of information on this aspect of the problem which so far does not present a coherent picture. A. E. Owen (Westinghouse Resoarch Laboratories) contributes a report on electric conduction and dielectric relaxation in glass, in which, after a brief review of the Zachariasen-Warren work, ho outlines the present-day theories of d.c. conductivity and relaxation, directing particular attention to the role of the alkali ion. He feels that, in spite of the present-day work, a quantitative understanding of even the simpler electrical phenomena in glass has still not been achieved. The final essay is by R. L. Coble (Massachusetts Institute of Technology) and J. E. Burke (General Electric Research Laboratory) on sintering. This covers a good deal of fairly well-established work, but is particularly interesting in its comments on the inhibition of discontinuous grain growth and on pore trapping.

The book in some curious way lacks impact, and one must hope that future volumes in this series will be more exciting. Howevor, it is a useful addition to the library and contains extensive bibliographies.

N. F. Astbury

\section{Encyclopedia of Chemical Technology}

By Kirk-Othmer. Executive Editor: Anthony Standen. Vol. 2: Aluminium Compounds to Azo Dyes. Second completely revised edition. Pp. $x v+910$. (New York and London: Interscience Publishers, a Division of John Wiley and Sons, Inc., 1963.) 338s.

TI

HE publication of the revised second volume of

'Kirk-Othmer' within a year of the publication of the first volume is a notable achievement, and full credit must be given to the editorial board on fulfilling their promise to publish two to three revised volumes per year of this excellent Encyclopedia of Chemical Technology.

This volume contains thirty-nine articles ranging from "Aluminium Compounds" to "Azo Dyes", the majority of which appeared in Volumes 1 and 2 of the first edition. Each article, written by a specialist, has been completely revised and extended. For example, "Amines", included in the first edition, has been replaced by three complete articles covering, "Amines aliphatic", "Amines fatty" and "Amines chloroalkyl". New leading articles covering material only briefly mentioned in the first edition include, the following subjects. "Antistatic A.gents", an article which reviews the theory and use of these agents in fabric and polymer technology. "Aquametry", a review of analytical methods for the determination of water, with special reference to instrumental techniques, such as nuclear magnetic resonance, infra-red and ultra-violet spectroscopy, etc. "Automobile exhaust control", a subject of increasing importance, dealing with the health hazards and methods of control of the exhaust gases from automobile engines.

The preface to the first edition stated that contributions from othor countries would be included in an attempt to widen the scope of the Encyclopedia beyond the limits of technology in the United States. In this edition attempts to do this have been made by including leading articles written by Swiss, French and Japanese authors. The lists of trade names, although still predominantly of American origin, have all been rovised and extended.

It is disappointing that so many of the cross-references that were presented and found so useful in the first edition have been omitted-a loss that will no doubt be overcome when the index volume is published. The omission of the review on "Analytical Chemistry" will, we hope, be replaced by the inclusion, in later volumes, of soparate articles on individual analytical procedures.

$$
\text { K. Freld }
$$

\section{A Manual of Experiments in Reactor Physics}

Edited by Prof. Frank A. Valentine. Pp. $x v+335$. (New York: The Macmillan Company; London: CollierMacmillan Ltd., 1963.) $55 s$.

$T$ is inevitable that any account of specialized experi1 monts using equipment available in modern laboratories, such as those catering for reactor physics students, must contain a certain amount of detailed description of items of equipment which are special to the country of origin. This means that accounts of experiments and details of how they are to be performed must inovitably lose some of their value in a country other than that which has the equipment readily available.

For non-American users, therefore, this is a fault from which $A$ Manual of Experiments in Reactor Physics suffers. However, despite this, it is generally so good an account as largely to make up for this defect. There is an excellent opening chapter on the elementary statistics of experiments, a subject which is so often neglected altogether or dealt with inadequately. This is followed by a short discussion of radioactivity, which includes a description of the method of analysis of decay curves. The standard methods of detection of particles are then described, together with a very short account of some electronic techniques. Also included in this chapter is an account of neutron sources. As a number of the experiments which are described later in the book require a pulsed-neutron source, there is a short discussion of the theory and methods of production of pulsed-neutron sources, and the final chapter in the introductory section (rather less than half the book) deals with radiological considerations relating to safety requirements in a reactor physics laboratory.

The remainder of the book describes actual experiments which fall into three broad categories; those requiring only a steady source of neutrons (ten experiments); those requiring a subscribed assembly and a steady source of neutrons (six experiments); and those requiring a sigma-pile or a subcritical assembly and a pulsed source of neutrons (seven experiments). All are well described according to a standard pattern of introduction, object, theory and method, materials and apparatus, procedure, results and discussion. It should, however, be noted that the theory given generally amounts only to a discussion of the necessary and relevant formulæ required and not to the derivation of them. However, very adequate references are given for the experimenter to be able to read these up for himself.

For those who wish to have ready-made descriptions of many important, yet relatively simple, experiments in reactor physics this is an excellent book, with the proviso that some of the particular pieces of equipment described will not be available outside American laboratories.
J. F. HILI 